\title{
Homostyle primroses re-visited. I. Variation in time and space
}

\author{
Jill Curtis and \\ C. F. Curtis
}

Church Farm Cottage, Evercreech, Somerset, U.K.

\begin{abstract}
Populations of Primula vulgaris L. generally consist of two self incompatible heterostyle morphs, but in Somerset, S.W. England, a third type, homostyle, also occurs and was studied in the 1940s and 1950s by J. Crosby and others. A more extensive mapping of the distribution and frequencies of the three morphs has now been carried out and 30 well defined local populations have been re-scored after $25-40$ years have elapsed. The observed changes in morph frequency were only slight but showed a frequency dependent pattern. This is contrary to the prediction of Crosby who expected the homostyles would increase in all cases because they self fertilise and can pollinate one of the heterostyle morphs. Computer simulations of this breeding system combined with other fitness variables showed that a restricted range of values for inbreeding depression, inviability of the homozygous homostyle and gene flow between populations would give frequency dependent change of the kind which was observed.
\end{abstract}

\section{INTRODUCTION}

Populations of the primrose (Primula vulgaris L.) generally consist of approximately equal numbers of two morphs: "pin", with a high stigma covered in long papillae and with low anthers containing small pollen grains, and "thrum" with a low stigma covered in short papillae and high anthers containing large pollen grains. Darwin (1877) showed that a self-incompatibility mechanism ensures that most seed is produced from cross fertilisation between pin and thrum plants. Crosby (1940) reported a third morph ("homostyle" or "long homostyle") at a high frequency in a wood in Somerset, S.W. England, with a stigma like that of pin but anthers like those of thrum. Crosby (1949) presented a distribution map of homostyles in Somerset and also in the Chiltern Hills (N.W. of London) and showed, by a map of 67 samples without homostyles, that they probably do not exist at appreciable frequency in other parts of England, Wales or Southern Scotland.

In $P$. sinensis Bateson and Gregory (1905) showed that pin was homozygous for a recessive $(s s)$ and thrum heterozygous for a dominant (Ss). In $P$. viscosa, Ernst (1933) showed that homostyles were generated at a measurable, but low, rate from heterostyles. Dowrick (1956) argued that this was probably because of rare cross-overs within the $S / s$ super-gene so that the factors determining the anatomy and compatibility of the gynoecium of pin become linked to those determining the androecium of thrum. It is assumed that the same applied to $P$. vulgaris homostyles since this accords with the facts that they are self compatible, their pollen is compatible with pin and their stigmas are compatible with thrum pollen, Furthermore, the homostyle supergene $\left(s^{\prime}\right)$ is dominant to $s$ and recessive to $S$ and homostyles can exist in the heterozygous $\left(s^{\prime} s\right)$ or homozygous $\left(s^{\prime} s^{\prime}\right)$ form (Crosby, 1949).

Crosby (1949) pointed out that if homostyle stigmas are generally self fertilised and homostyle pollen could fertilise pins, the homostyle supergene, $s^{\prime}$, would be expected to spread, other things being equal. This is because homostyle pollen would compete with thrum for the fertilisation of pin, but thrum pollen would not have much chance of competing to fertilise homostyle stigmas. Thus thrums would be expected to decline, leaving pin pollen with little chance of achieving fertilisation, so that pins would follow thrums to extinction. However, if homozygous homostyles had reduced fitness, the end-point would be a balanced polymorphism of homostyles and pins. The data of Crosby (1949) appear to give support to these ideas in that many populations were found to be scattered along the expected trajectory of evolutionary change, i.e., where there were moderate numbers of homostyles there were few thrums and where 
homostyles were very frequent there were no thrums, but limited numbers of pins.

Crosby (1949) raised the question of whether an additional advantage to the homostyle would be that, being able to self-fertilise, it did not depend on pollen transport from plant to plant and that if insect pollinators were in short supply the homostyle might therefore be able to set more seed. Piper et al. (1984) have shown that homostyles do indeed tend to set more seed than pins and thrums. This is due to limitation of pollen transfer to the latter, as shown by the fact that adding compatible pollen artificially to the cross fertilising types raised their seed set to that of homostyles. As might be expected, the advantage to homostyles in this respect was found to vary between different years and places. Charlesworth and Charlesworth (1979) consider that inbreeding depression may counterbalance the advantages the homostyles gain by self-fertilisation.

Bodmer (1960) and Ford (1964) pointed out that it was difficult to believe that the evolutionary elimination of the thrums by homostyles had been "waiting" for an exceedingly rare cross-over event to occur and now that this had occurred the elimination would proceed remorselessly to completion, and furthermore that the cross-over had occurred apparently independently in two separate areas (Somerset and the Chilterns). Bodmer (1957, 1960, 1984) argued that the selective advantage of homostyles was slight or non-existent because they were usually not self-fertilised and he presented data based on up to 13 years' counts which seemed to show some declines in homostyle frequencies. In the present paper we present data on counts after the lapse of much longer periods of time. Evidence against frequent cross pollination of homostyles is presented by Crosby (1958), Piper et al., (1984) and in the accompanying paper (Curtis, Jones and Curtis, 1985).

\section{RESULTS AND DISCUSSION}

\section{Overall distribution of homostyles}

Fig. 1 shows our counts between 1978 and 1984 of the frequencies of the three morphs in primrose populations in Somerset and North Dorset. With a few exceptions data are only shown where we were able to find 100 plants. Where plants were touching and of the same phenotype we only counted them as one because of the possibility of clonal spread. To identify thrums and homostyles it is necessary to pick a flower; in the interests of

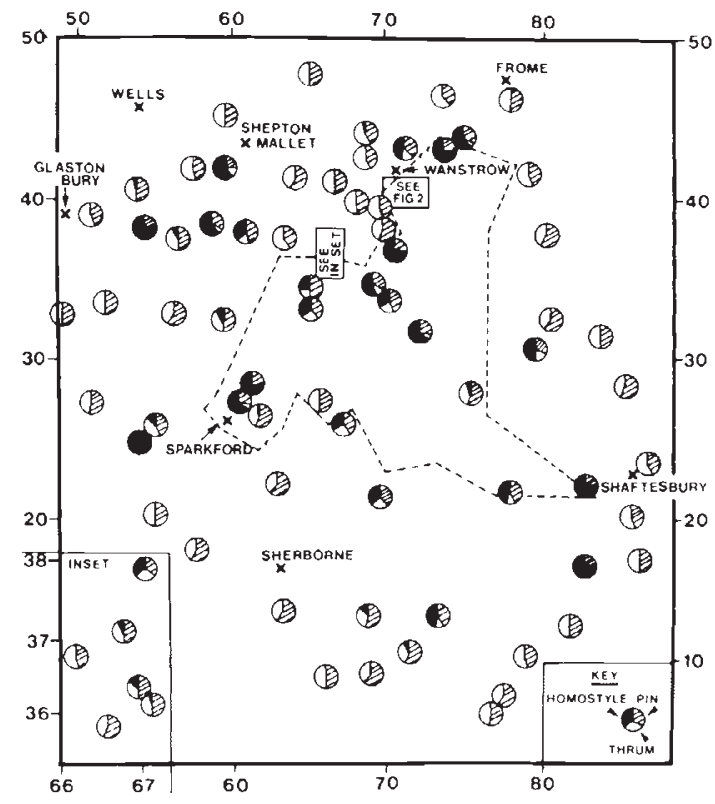

Figure 1 Map of the distribution of the three primrose morphs in Somerset and North Dorset. The scales refer to the kilometre national grid within the ST 100 kilometre square. The positions of the populations are indicated by the centres of the circles except for a few cases of nearby populations when both symbols have had to be slightly displaced.

conservation we did not do this from plants with less than four flowers and all such small plants were omitted from our samples. In the later stages of the work, in the occasional cases of doubt in separating thrums and homostyles we used a lens to observe the length of the stigma papillae of unpollinated flowers. We attempted to define the limits to the distribution of homostyles by finding a ring of points in which the population consists of pins and thrums only.

The distribution of homostyles was similar to that shown by Crosby (1949) with some exceptions. We have derived the apparent outer limit of homostyles from his map and this is shown by the dashed line in fig. 1. He commented that he had not yet fully investigated the south of the area and we found homostyles some distance into North Dorset (south west of Shaftesbury) before reaching an apparently well defined limit. Crosby (1949) stated that primroses were absent on the clay soils south west of Sparkford, but by careful searches of copses we found them several kilometres further south and west, including a remarkable population of 106 plants at grid reference 557255 which consisted of homostyles only. This is apparently the only monomorphic primrose population of any 
size which has ever been reported. It is situated 240 metres from a polymorphic population (fig. 1) and presumably it arose by the founder effect from the accidental transport of a homozygous homostyle seed.

To the north west, Crosby (1949) thought he had defined the limit of homostyle distribution: we also found this apparent limit but then found several populations beyond this limit to the north west. This cluster is now only tenuously connected to the main body of homostyle populations, but there may formerly have been more obvious connections in the region of grid reference 610350 where primroses are now difficult to find, but may not have been before the advent of modern agriculture.

With this doubtful exception we have so far found no isolated "enclaves" of homostyles and the conception of Crosby $(1949,1960)$ of them spreading somewhat haphazardly but from a single centre of origin is not inconsistent with our data. Such differences as there are between our distribution map and Crosby's need not be due to an actual spread of homostyles over the last 30-35 years, but could be explained by our more extensive searches than those of Crosby (1949). J. Crosby has informed us that he has much unpublished data which agree with the N.W. and S.E. extensions of the known homostyle range described above.

\section{Populations in the Sparkford area}

A large number of samples were studied in the past by R. A. Fisher, J. Crosby, W. F. Bodmer and others in the Sparkford area and detailed data for five populations collected from 1940 to 1954 are given by Crosby (1940) and Bodmer (1960). We have re-examined some of these populations in 1982 and 1983. Crosby's data derived from two "slightly overlapping" populations in Sparkford Wood and Bodmer divided the wood into two populations: the south and north-west. The wood has become extensively colonised by bluebells (Endymion nonscriptus (L.) Garcke) and there are now almost no primroses in either of these two sectors of the wood. We found plants in the east and north-east of the wood, however, and our data from this area are given in table 1 . There was significant heterogeneity between the two populations distinguished by Bodmer (1960) in Sparkford Wood. Counts carried out over seven years of the south population showed a significant downward trend of the proprtion of homostyles and an upward trend of pins (see table 1 for the counts in 1941 and 1948). Five counts in the north-west population between 1941 and 1954 showed significant heterogeneity but there was no trend (the data for 1941 and 1954 are given in table 1). Our data collected in 1982 are similar to the overall average of the data from 30-40 years ago and though we cannot exactly identify the area of the wood where we found primroses with any of the populations studied before, the comparison suggests stability rather than a major trend. The population in Lear's Copse for which Bodmer (1960) gives data for 1943-54 contained very few thrums and our data for 1983 are very similar (table 1). Our data for Wilford's Copse, where there are very

Table 1 Data from Sparkford area

\begin{tabular}{|c|c|c|c|c|c|c|}
\hline Year & Site & Pin & $\begin{array}{l}\text { Percentage of: } \\
\text { Thrum }\end{array}$ & Homostyle & $\begin{array}{l}\text { Total } \\
\text { counted }\end{array}$ & Reference \\
\hline \multirow{3}{*}{1940} & Sparkford Wood* & & & & & \\
\hline & Two "slightly & $31 \cdot 6$ & $3 \cdot 4$ & $65 \cdot 0$ & 323 & Crosby (1940) \\
\hline & overlapping" pops. & $23 \cdot 1$ & $2 \cdot 4$ & $74 \cdot 5$ & 628 & Crosby (1940) \\
\hline 1941 & South & $16 \cdot 7$ & 0.9 & $82 \cdot 4$ & 312 & Bodmer (1960) \\
\hline 1948 & South & $27 \cdot 3$ & 0.5 & $72 \cdot 3$ & 205 & Bodmer (1960) \\
\hline 1941 & Northwest & $34 \cdot 2$ & $12 \cdot 5$ & $53 \cdot 3$ & 120 & Bodmer (1960) \\
\hline 1954 & North west & $39 \cdot 0$ & $4 \cdot 0$ & $57 \cdot 0$ & 100 & Bodmer (1960) \\
\hline 1982 & East and N.E. & $30 \cdot 5$ & $3 \cdot 1$ & $66 \cdot 4$ & 292 & Present study \\
\hline 1943 & Lear's Copset & $14 \cdot 5$ & $2 \cdot 4$ & $83 \cdot 1$ & 83 & Bodmer $(1960)$ \\
\hline 1954 & Lear's Copset & $22 \cdot 4$ & 0 & $77 \cdot 6$ & 237 & Bodmer (1960) \\
\hline 1983 & Lear's Copset & $20 \cdot 2$ & 0 & $79 \cdot 8$ & 84 & Present study \\
\hline 1942 & Wilford's Copset & $54 \cdot 3$ & $43 \cdot 6$ & $2 \cdot 1$ & 188 & Bodmer (1960) \\
\hline 1948 & Wilford's Copse $\ddagger$ & $58 \cdot 5$ & $37 \cdot 5$ & $4 \cdot 0$ & 176 & Bodmer (1960) \\
\hline 1983 & Wilford's Copse $\ddagger$ & $53 \cdot 5$ & $43 \cdot 5$ & $2 \cdot 8$ & 317 & Present study \\
\hline
\end{tabular}

* Map ref. ST 613275.

† Map ref. ST 620285 .

$\$$ Map ref. ST 624266 . 
few homostyles, are very similar to those given by Bodmer (1960) which were collected between 1942 and 1948 (table 1). Bodmer (1960) emphasised the significant downward trend of homostyles and the upward trend of thrums between 1942 and 1949 in Laurel Copse hedgerow. Unfortunately we could not investigate whether this trend has continued because both the copse and the hedgerow have been cleared and the primroses are no longer there.

\section{Populations in the Wanstrow area}

A more convincing test of whether homostyle frequencies are showing an upward or downward trend with time can be made from data for an area just south of the village of Wanstrow (map ref. 712417). Symbols indicating homostyle:thrum ratios for populations in this area in the 1950s were published in fig. 3 of Crosby (1960) and the author very kindly provided us with the details of counts on which these symbols were based, together with a map indicating the exact location of these populations. Over the last 13 years we have located as many of these populations as still exist. Table 2 records the numbers and fig. 2 indicates pin: thrum: homostyle frequencies in Crosby's samples in 1955-57 and our counts in 1982-84 for the same populations. We have only included cases where we are quite sure that the locations are identical and where both samples exceeded 50 plants. In a few cases, to reach this sample size, we have pooled data for near neighbour populations between which there was no significant heterogeneity. The symbols are assigned the serial numbers given to them by Crosby. In the case of the smaller populations, we counted all the plants of acceptable size that we could find. However, from the larger populations we counted samples of about 100 plants. Crosby's data were in most cases based on samples, though he records that in many cases his sampling was "heavy", i.e., included large proportions of the populations.

Fig. 2 shows remarkable similarity in the frequencies in the same location over several decades despite great differences in the frequencies over a few hundred metres: in the south west of the area there are no homostyles, but there are over 50 per cent in the centre and east.

From the data in table 2 it was found that only at sites $887 / 888$ and 894 were there significant $\chi^{2}$ values $(P<0.05)$ from comparing the number of

Table 2 Counts on the Wanstrow populations mapped in Fig. 2

\begin{tabular}{|c|c|c|c|c|c|c|}
\hline Site & Pin & $\begin{array}{l}\text { 1955-57 } \\
\text { Thrum }\end{array}$ & Homostyle & Pin & $\begin{array}{l}1982-84 \\
\text { Thrum }\end{array}$ & Homostyle \\
\hline 39 & $28^{*}$ & $13^{*}$ & $52^{*}$ & 62 & 29 & 74 \\
\hline 677 & 53 & 26 & 35 & 106 & 82 & 120 \\
\hline $678 \& 679$ & 69 & 73 & 3 & 82 & 55 & 4 \\
\hline $735 \& 736$ & 41 & 7 & 79 & 18 & 5 & 34 \\
\hline $739 \& 740$ & 39 & 11 & 97 & 85 & 12 & 157 \\
\hline 741 & 24 & 10 & 42 & 49 & 13 & 47 \\
\hline 751 & 91 & 103 & 20 & 36 & 29 & 9 \\
\hline 752 & 48 & 48 & 0 & 54 & 55 & 0 \\
\hline 761 & 43 & 7 & 64 & 34 & 9 & 69 \\
\hline 762 & 32 & 13 & 58 & 38 & 14 & 59 \\
\hline 764 & 23 & 2 & 53 & 50 & 9 & 76 \\
\hline 768 & 24 & 12 & 65 & 17 & 9 & 28 \\
\hline 770 & 24 & 8 & 71 & 21 & 15 & 101 \\
\hline 771 & 43 & 25 & 36 & 26 & 9 & 19 \\
\hline 883 & 59 & 20 & 109 & 29 & 7 & 40 \\
\hline $887 \& 888$ & 23 & 8 & 23 & 26 & 6 & 65 \\
\hline 889 & 60 & 47 & 22 & 40 & 24 & 19 \\
\hline 893 & 28 & 18 & 3 & 45 & 45 & 10 \\
\hline 894 & 57 & 37 & 5 & 45 & 40 & 16 \\
\hline 903 & 59 & 26 & 22 & 45 & 32 & 14 \\
\hline 945 & 27 & 21 & 54 & 42 & 28 & 46 \\
\hline 946 & 59 & 10 & 59 & 26 & 7 & 45 \\
\hline 948 & 40 & 16 & 60 & 37 & 7 & 64 \\
\hline 960 & 67 & 17 & 103 & 21 & 6 & 36 \\
\hline 1009 & 26 & 28 & 4 & 52 & 50 & 13 \\
\hline 1032 & 34 & 24 & 10 & 29 & 19 & 11 \\
\hline 1033 & 31 & 50 & 0 & 54 & 43 & 4 \\
\hline
\end{tabular}

* Counts from 1946 


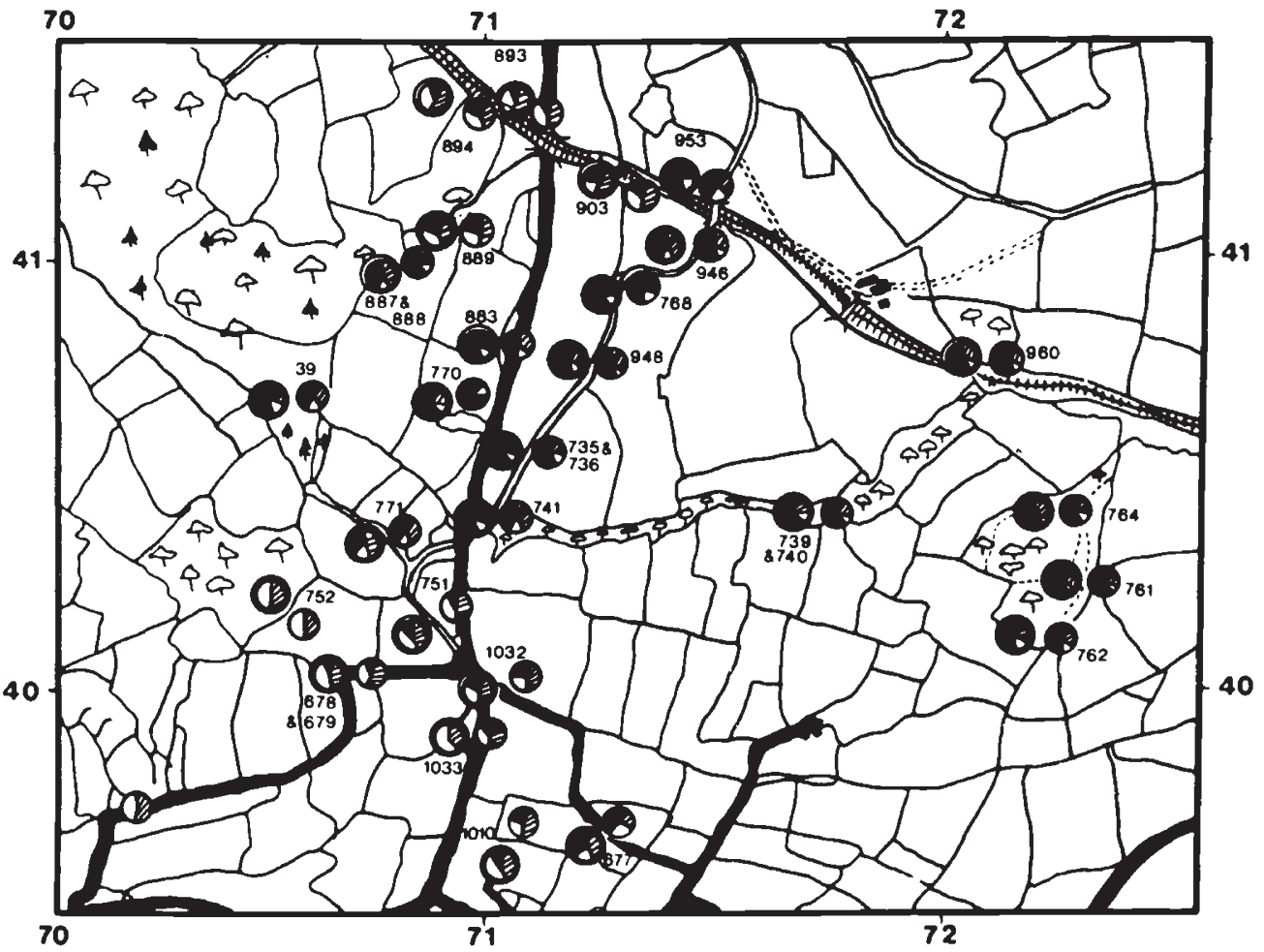

Figure 2 The frequencies in 27 populations south of Wanstrow found by J. Crosby in 1955-57 (data for one population from 1946) and our own counts at the same locations in 1982-84. The three morphs are symbolised as shown in the key in fig. 1; the circle with the double outline represents the earlier counts and the neighbouring circle with the single outline represents the corresponding recent count. The location of the population is at a point equidistant between the centres of the circles. The serial numbers assigned to the populations by Crosby are shown in this figure and in table 2 .

thrums and homostyles between 1955-57 and 1982-84. Site 1033 showed a nearly significant difference by Fisher's exact test. If pins are included in the comparisons these three sites are again the only ones showing significant $(P<0 \cdot 05)$ change. However, these tests of whether the observed differences can be explained by sampling error may be considered too stringent when in many cases all or nearly all of the plants in the populations were scored.

Fig. 3 shows the data in terms of homostyles/(homostyles + thrums), i.e., $H /(H+T)$, a measure used by Crosby (1949) as it is sensitive to the expected evolutionary competition of thrums and homostyles. The graph plots the data for each Wanstrow population in 1955-57 against the corresponding data for 1982-84. If there were only random changes over the years the points would be scattered on either side of the straight line at $45^{\circ}$. However, in fact there is a markedly frequency dependent pattern, i.e., nearly all the points at low initial $H /(H+T)$ values lie above the line and most of the points at high initial values lie below it. We omitted from further analysis the two populations which initially had no homostyles and the one population which showed no change. We then find that of the 12 populations with $H /(H+T)$ value of below 0.75 in $1955-57,10$ showed an apparent slight upward change by $1982-84$, but 8 of the 12 populations initially above 0.75 showed an apparent slight downward trend. This difference is statistically significant $\left(\chi^{2}\right.$, with Yates' correction, $=4 \cdot 28, P<0 \cdot 05)$.

As a simple test of whether the direction of change varies with ecological factors we distinguish in fig. 3 shaded woodland populations (which tend to flower late), from those more exposed to sunlight along hedgerows and banks. From fig. 3 this factor does not appear to be correlated with direction of evolutionary change. The woodland populations mostly had higher than average $H /(H+T)$ values but this seems to be due to the cline from south west to north east and the fact that most of the woodland was to the east of the area (fig. 2). 


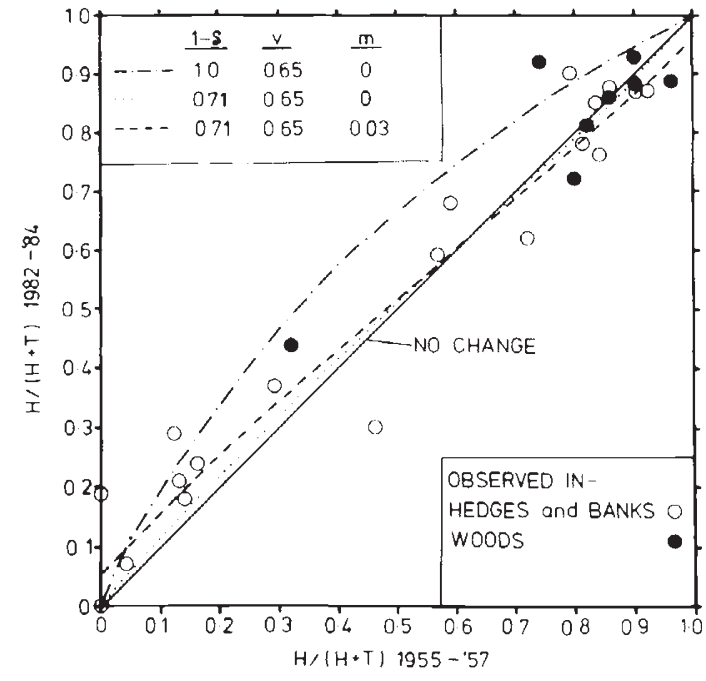

Figure 3 Graphical comparison of the observed values of $H /(H+T)$ in 1955-57 and 1982-84 and predictions from the computer model for the specified values of $1-\delta$ (Charlesworth \& Charlesworth, 1979), the viability of homozygous homostyles $(v)$ and the gene flow between populations, $m$. Open and solid circles distinguish un shaded populations in hedges and banks from shaded woodland populations. The points would follow the solid line at $45^{\circ}$ if there had been no change over the years.

\section{Computer simulations}

Crosby (1949) constructed a mathematical model of a population including pins, thrums, heterozygous homostyles and homozygous homostyles. The assumptions of the model were clearly stated, and included 100 per cent self-fertilisation of homostyles, equal seed set of all genotypes, 10 per cent selfing of pins and a sub-normal value for the fitness of homozygous homostyles, $v$. He concluded that a value of 65 per cent of normal for $v$ best fitted the fact that he found several populations with 80 per cent homostyles and 20 per cent pins and he found no large population monomorphic for homostyly, The value of 65 per cent for $v$ would lead to a balanced polymorphism of the $s^{\prime}$ and $s$ genes with an $80: 20$ ratio of homostyles: pins.

We constructed a computer model similar to Crosby's model but which allowed for the possibility of some cross fertilisation of homostyle stigmas with pollen from thrum or other homostyle plants. Such outcrossing leads to the production of a fifth genotype, $S s^{\prime}$, which is included in our model and assumed to have all the properties of thrum. The factor $(1-\delta)$ of Charlesworth and Charlesworth (1979) is also included as a parameter in our model, i.e., selfing can either be assumed to lead to subnormal production of viable seeds because of inbreeding depression or super-normal production because of the avoidance of the need for pollinating insects (Piper et al., 1984). If homostyles are more vulnerable to complete sterilisation by slug or snail predation because both the anthers and stigma are at the top of the flower (Richards, 1984, quoting (rosby) this would have an effect similar to a reduction in $(1-\delta)$.

In running our model we assumed 90 per cent of selfing by homostyles: an estimate based on the data so far available from seed collected in the field and germinated and grown in the greenhouse (Piper et al., 1984; Curtis et al., 1985). We used both very high and very low homostyle frequencies as the initial conditions for a series of simulations with various values of $(1-\delta)$ and $v$. We assumed that the interval between $1955-57$ and 1982-84 corresponded to three primrose generations, using Crosby's (1960) estimate of a primrose generation time of nine years.

Fig. 3 shows that if $(1-\delta)$ is unity and $v$ is 0.65 (as assumed by Crosby, 1949), considerable increases of $H /(H+T)$ would have been expected over the whole range of initial values. This is contrary to the observed pattern of frequency dependent direction of change and indeed eleven of the individual populations showed observed numbers of the morphs in 1982-84 which differed significantly $(P=0 \cdot 01$ to $<0 \cdot 001)$ by $\chi^{2}$ tests from the expectations after three generations of evolution with these fitness values.

If $(1-\delta)$ remains at unity, reducing $v$ even to zero does not prevent the ultimate elimination of thrums (Crosby 1949). However, fixing $v$ at $1 \cdot 0$ and varying $(1-\delta)$ showed that homostyles were favoured at all frequencies down to $a(1-\delta)$ value of 0.52 and thrums were unconditionally favoured if $(1-\delta)$ is reduced to $0 \cdot 50$. If both $v$ and $(1-\delta)$ are varied there are limited ranges of values in which frequency dependent selection would occur, e.g., $v=0.65,(1-\delta)=0.71$ (fig. 3 ). For the same value of $v$, lowering $(1-\delta)$ to 0.65 or raising it to 0.85 made the directions of selectibn frequency independent. At $(1-\delta)=0.71$ the deviation from the "no change" line is very small and does not fit the observed data appreciably better than the "no change" line. One possible cause of greater deviation from this line could be the elapse. of more than the supposed three generations, i.e., a generation time much shorter than 9 years. It is hoped that more data on primrose generation times will soon be available (M. Boyd, personal communication). 
As pointed out to us by B. Charlesworth another source of frequency dependent change could be gene flow from neighbouring populations. The gene frequency in the population donating pollen or seeds would, on average, be less extreme than in those recipient populations with very high or very low gene frequencies, thus leading to frequency dependent change of the observed kind. The expected change per generation due to gene flow, $\Delta p$, is given by

$$
\Delta p=-m(p-\bar{p})
$$

where $m$ is the proportion of genes contributed per generation from outside the population, and $\bar{p}$ is the average gene frequency in all contributing populations.

The data of Cahalan and Gliddon (1985) show that the average distance of pollen and seed dispersal is very short. However, this probably does not exclude occasional much longer distance dispersal due to exceptional events. Assuming $m=0.03$, taking the mean value of $H /(H+T)$ as 0.57 for the whole Wanstrow area and retaining the assumptions of a 9 year generation time and $v=0.65$, $(1-\delta)=0 \cdot 71$, the effect of gene flow was calculated and is shown in fig. 3 considerably to increase the frequency dependent deviation from the "no change" line and to fit the observed data considerably better than the "no change" line.

Dispensing with the assumption of reduced $(1-\delta)$ but retaining the assumption of gene flow does not give a good fit to the observed data. Bodmer (1984) objects to the assumption of reduced viability because it is inconsistent with the observed data from breeding experiments. However, very little comparative data on the germination rate following inbreeding and outcrossing are available so far, and reduced viability might be expressed only in competitive wild conditions and not in the experimental garden or greenhouse.

\section{Longer term changes}

Fig. 3 suggests that the Wanstrow populations are now tending towards an equilibrium of the three morphs but this would not explain how high homostyle frequencies, with few or no thrums, ever came to be established in nearby parts of Somerset (flg. l). This could be explained if in the past $(1-\delta)$ was considerably higher than it is now. The present lower value could hardly have come about through an increase in the severity of inbreeding depression: if anything one would expect an opposite tendency. We therefore suppose that for a considerable period in the past there was a great advantage of selfing in not being dependent on pollinating insects and this counter-balanced the effects of inbreeding depression. In recent decades it would appear that pollinating insects have been more readily available than formerly so that $(1-\delta)$ has averaged less than unity and, taking into account the fundamental advantage for a gene which allows selfing, homostyles have tended towards an equilibrium with the other morphs.

Piper et al., (1984) have given evidence that the seed set by homostyles relative to that of the other morphs varies from place to place and from year to year. Thus it may be that for climatic reasons this advantage for homostyles has on average declined in recent years. It may be noted that the proposed direction of change is the opposite of what would have been expected if the advent of agricultural pesticides had a major adverse effect on pollinating insects. However, Somerset, being mainly pastoral rather than an arable farming area, would have been expected to be less affected by this factor than the eastern counties of England.

The locations of the populations in our study have been indicated precisely and we hope that after a few more decades have elapsed the primrose populations will still exist and that meaningful comparisons can be made with the present data.

Acknowledgements We are very grateful to Jack Crosby for kindly providing his detailed counts and maps of primrose populations in the Wanstrow area and for his comments. We thank Jo Lines and Margaret Chandler for assistance with computing and Deborah Charlesworth, Brian Charlesworth and David Jones for their comments on the manuscript.

\section{REFERENCES}

BATESON, W. AND GREGORY, R. P. 1905. On the inheritance of heterostylism in Primula. Proc. Roy. Soc. B, 76, 581-586. BODMER, W. F. 1958. Natural crossing between homostyle plants of Primula vulgaris. Heredity, 12, 363-370.

BODMER, W. F. 1960. Cienetics of homostyly in populations of Primula vulgaris. Phil. Trans. Roy. Soc. B, 242, 517-549.

BOIMMER, W. F. 1984. Sex and generations of primroses. Nature, 310,731 .

CAHALAN, C. M. AND GLIDDON, C. 1985. Genetic neighbourhood sizes in Primula vulgaris. Heredity, in press.

CHARLESWORTH, D. AND CHARLESWORTH, B. 1979. The evolutionary genetics of sexual systems in flowering plants. Proc. Roy. Soc. B., 205, 513-530.

CROSBY, J. 1940. High proportions of homostyle plants in populations of Primula vulgaris. Nature, 145, 672-673.

CROSBY, J. 1949. Selection of an unfavourable gene complex. Evolution, 3, 212-230.

CROSBY, J. 1959. Outcrossing on homostyle primroses. Heredity, 13, 127-131. 
CROSBY, J. 1960. The use of electronic computation in the study of random fluctuations in rapidly evolving populations. Phil. Trans. Roy. Soc. B, 242, 551-572.

CURTIS, C. F., JONES, D. A., AND CURTIS, J. 1985. Homostyle primroses re-visited. 2. Estimate of the selfing rate from the progeny of wild plants. Submitted for publication.

I ARWIN, C. 1877. The Different Forms of Flowers on Plants of the same Species. John Murray, London.

DOWRICK, V. P. J. 1956. Heterostyly and homostyly in Primula obconica. Heredity, 10, 219-236.
ERNST, A. 1933. Weitere Untersuchungen zur Phänanalyse, zum Fertilitäts-problem und zur Genetik Heterostyler Primeln 1. Primula viscosa. Archiv der J. Klaus Stift., 8, 1-215.

FORD, E. B. 1964. Ecological Genetics, Chapman \& Hall, London.

PIPER, J. G., CHARLESWORTH, B. AND CHARLESWORTH, D. 1984. A high rate of self-fertilisation and increased seed fertility of homostyle primroses. Nature, 310, 50-51.

RICHARDS, A. J. 1984. The sex life of primroses. Nature, 310, $12-13$. 